\title{
Nine Level H Bridge Grid Connected Inverter Operated Photovoltaic Module Using Matlab
}

\author{
R.Vajubunnisa Begum ${ }^{1}$ Dr. N.Shanmugasundaram², S. Abdul Kalam ${ }^{3}$ \\ ${ }^{1}$ Associate Prof.Department of Electronics and Communication Science, JBAS College for Women, Chennai \\ 600018, India \\ ${ }^{2}$ AssociateProf. Department of Electrical and Electronics Engineering, VELs University, Chennai-600117, India. \\ ${ }^{3}$ Assistant Prof. Department of Mechanical Engineering, Sri Muthukumaran Institute of Technology, Chennai \\ 600069, India
}

\begin{abstract}
In this paper, the topology of H Bridge configuration meet many demands in the Industry of Power Electronics with the nearest progress in MOSFET switches the cost, size and installation area are highly reduced. It is a transformerless process in order to increase the quality of the Power with reduction in losses and stress. In the PV panel the solar radiance method is employed for energy harvesting in Agriculture site. Finally, the simulation relations using MATLAB / Simulink show the applicability and performance of the proposed model in $P V$ storage system for the prediction of Boosted PV output power.
\end{abstract}

Indexwords: $H$ - bridge multilevel inverters, Boost Converter, Photovoltaic module.

\section{Introduction}

Environmental concern and the necessary to find cleaner energy sources have resulted in the fast increasing saturation of Generation and distribution sector from renewable resources like solar power sources. But as penetration of variable generation sources reaches and exceeds the 10-30\% range, matching supply to load will begin to fake a significant confront. With such transformations intimidating in the future, energy storage will become vital to creating a power system that can handle both the changeability and unpredictability of renewable resources in an increasingly complex and assorted grid. The controlling and coordinating BES units in a PV storage system for smoothing the intermittency of the solar resource and changing output to more closely match the load side view. The PV storage system is modeled as turned in optimization problem and Model Predictive Control (MPC) structure solves the optimization problem using external price signals and predictions of PV output at each time step. Our computation consists of an asymmetric least squares fit of the PV output data with a linear error correction to handle uncertainties and provide forecasts to enable dynamic power forecast.i1][2][3][4] Energy harvesting from ambient energy sources together with sunlight, wind, and tidal wave can present unrestrained and unlimited power supply for entrenched systems. However, the harvested energy exhibits intermittency characteristics. For instance, the output power of a photovoltaic (PV) panel at noon is an order of scale higher than that in the morning or evening.[5]

\section{(A) MODIFIED H - BRIDGE MLI:}

\section{Level Cascaded Modified H - Bridge Multilevel Inverter}

The pure sinusoidal wave is difficult to set from a simple single phase $\mathrm{H}$ - bridge inverter. Wherein, the concept of multilevel inverters in which the complete inverter system joined together to present the output that resembles to sine wave inverters. We can get pure sinusoidal to obtain $n$ level for $(n-1) H-$ bridges with four MOSFET switches in each bridge with the adjustment in delay and having a proper capacitor in the whole inverter system. Figure 1 shows the subsystem of $\mathrm{H}$ - bridge inverter using MOSFET switch.

Multilevel inverter provides many advantages such as improving the output voltage waveform, reducing voltage stress on the load and electromagnetic interference problems, higher efficiency, less distortion and switching frequency[9-13]. The development of a 9 level cascaded $\mathrm{H}$ - Bridge of a 9 level cascaded $\mathrm{H}-$ bridge MLI has implemented for medium and high voltage renewable energy system such as photovoltaic. The $\mathrm{H}$ - bridge configuration with addition of classical $\mathrm{H}$ bridge cells can be easily achieved for higher levels due to its modular and simple structure. The soft switching techniques can be applied in order to get the following aspects. They are 1.Elimination of transformer. 2. Easy packaging due to its simplicity and comprises minimum components. 


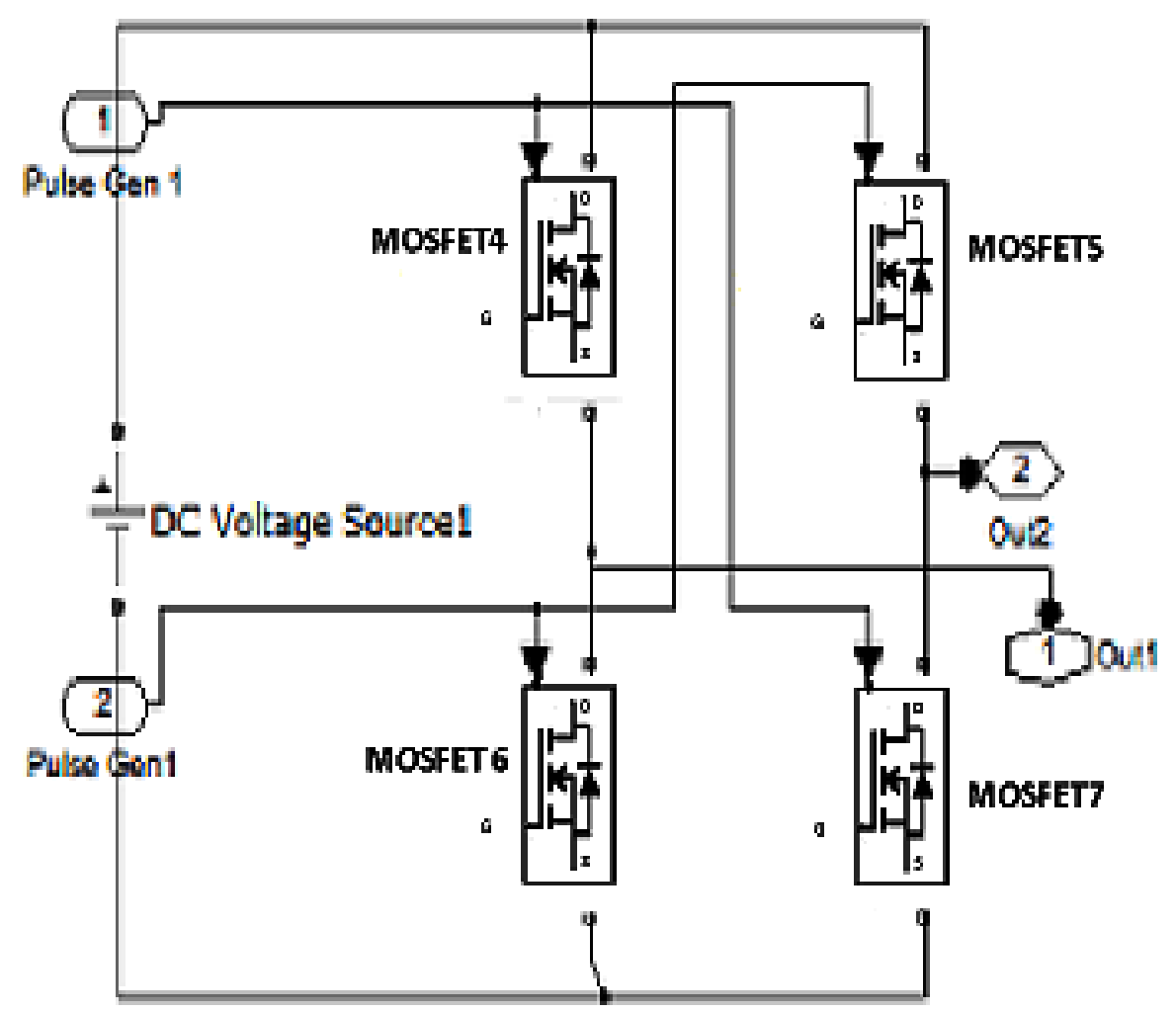

Fig. 1 Subsystem of $\mathrm{H}$-bridge inverter

Each $\mathrm{H}$ - bridge module is made by four bidirectional conducting four unidirectional blocking MOSFET switches S1, S2, S3, and S4. The modification of the classical H - bridge is shown in Figure 2.

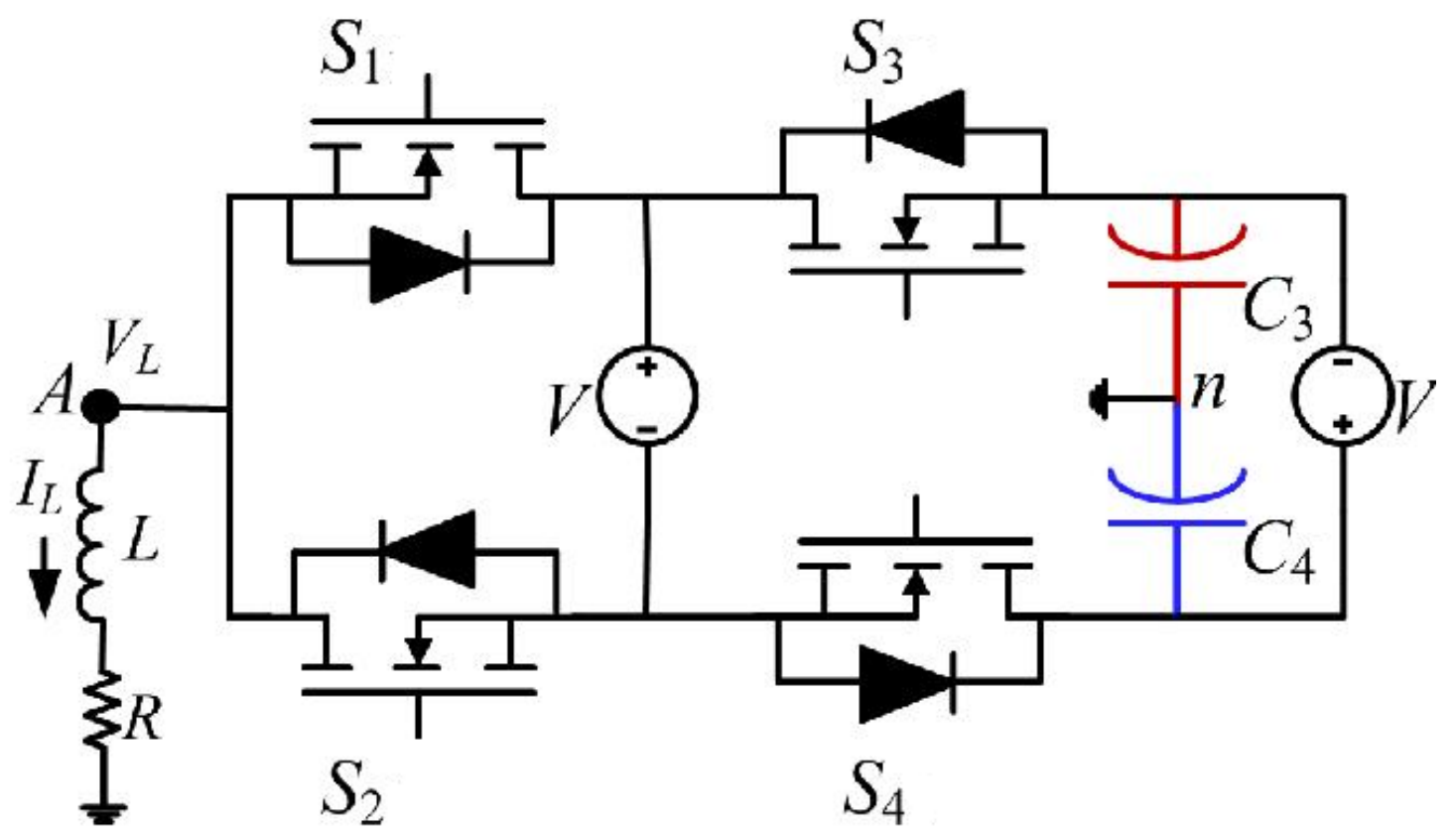

Fig. 2. MHB module of proposed MLI.

The pair of switches $(\mathrm{S} 1, \mathrm{~S} 2)$ and $(\mathrm{S} 3, \mathrm{~S} 4)$ with proper switching states as listed in Table 1 gives the output voltage levels $-\mathrm{V} / 2,-3 \mathrm{~V} / 2,+\mathrm{V} / 2$ and $+3 \mathrm{~V} / 2$. 
Table I: Switching states and output voltages of MHB

\begin{tabular}{|l|l|l|l|l|l|l|l|}
\hline S.No & S1 & S2 & S3 & S4 & C3 & C4 & VL \\
\hline 1 & High & Low & High & Low & $\downarrow$ & $\uparrow$ & $-\mathrm{V} / 2$ \\
\hline 2 & Low & High & Low & High & $\downarrow$ & $\uparrow$ & $-3 \mathrm{~V} / 2$ \\
\hline 3 & Low & High & Low & High & $\uparrow$ & $\downarrow$ & $+\mathrm{V} / 2$ \\
\hline 4 & High & Low & Low & High & $\uparrow$ & $\downarrow$ & $+3 \mathrm{~V} / 2$ \\
\hline
\end{tabular}

$\uparrow$ - Charge $\quad \downarrow$-Discharge

To enable natural balancing of capacitors and reduce one source, two capacitors and one DC source are employed (14) the proposed MHB module is investigated through an inductive load as shown in Figure 2.

The voltage balance between two capacitors is assured by a charge balance control method (15). In this method, the switching counts are increased in higher number, but the proposed MHB module has proved that there is no redundancy in the switching states. At the same time, natural balancing of capacitors is guaranteed in this module.

(B) PROPOSED THREE PHASE 9 LEVEL HYBRID MODULAR STRUCTURES:

The proposed MLI in each phase can be developed by combining the MHB and TTL inverter structure. This topology can produce 9 voltages levels $0,+\mathrm{V} / 2,+\mathrm{V},+3 \mathrm{~V} / 2,+2 \mathrm{~V},-2 \mathrm{~V},-3 \mathrm{~V} / 2,-\mathrm{V},-\mathrm{V} / 2$ are listed in table II.

Table II : Switching states and output voltages of proposed symmetrical 9 level MLI

\begin{tabular}{|l|l|l|l|l|l|l|l|l|}
\hline S.No & S1 & S2 & S3 & S4 & TR1 & TR2 & P & VR \\
\hline 1. & High & Low & High & Low & High & Low & Low & 0 \\
\hline 2. & Low & High & Low & High & Low & Low & High & $+\mathrm{V} / 2$ \\
\hline 3. & High & Low & Low & High & Low & High & Low & $+\mathrm{V}$ \\
\hline 4. & High & Low & Low & High & Low & Low & High & $+3 \mathrm{~V} / 2$ \\
\hline 5. & High & Low & Low & High & High & Low & Low & $+2 \mathrm{~V}$ \\
\hline 6. & High & Low & High & Low & Low & Low & High & $-\mathrm{V} / 2$ \\
\hline 7. & Low & High & High & Low & High & Low & Low & $-\mathrm{V}$ \\
\hline 8. & Low & High & High & Low & Low & Low & High & $-3 \mathrm{~V} / 2$ \\
\hline 9. & Low & High & High & Low & Low & High & Low & $-2 \mathrm{~V}$ \\
\hline
\end{tabular}

The TTL inverter structure with combination of six unidirectional switches for 3 phases in which each phase can produce voltage levels $0, \mathrm{~V} / 2$ and $-\mathrm{V} / 2$ listed in table III.

Table III: Switching states and output voltages of TTL inverter

\begin{tabular}{|l|l|l|l|l|l|l|l|l|l|l|}
\hline S.No & TR1 & TR2 & A & TY1 & TY2 & B & TB1 & TB2 & C & VRYBN \\
\hline 1 & Low & Low & High & Low & Low & High & Low & Low & High & 0 \\
\hline 2 & High & Low & Low & High & Low & Low & High & Low & Low & + V/2 \\
\hline 3 & Low & High & Low & Low & High & Low & Low & High & Low & - V/2 \\
\hline
\end{tabular}

The MHB modules in each Phase can be implemented to any level ' $n$ ' as shown in figure 3 .

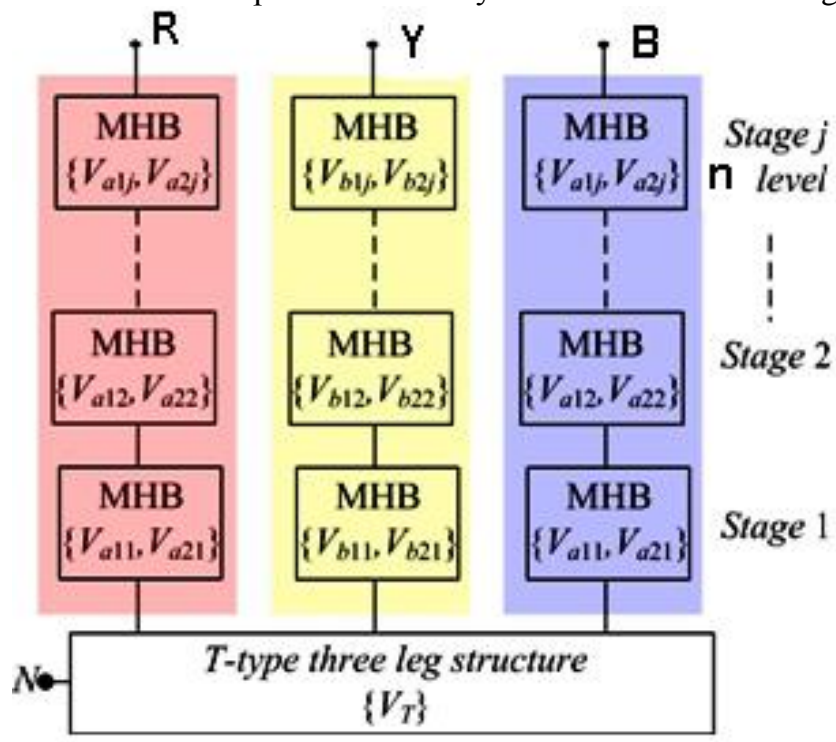

Fig. 3 Proposed three phase n level hybrid cascade modular (HCM) MLI structure 


\section{A. INTRODUCTION}

\section{Boost Converter Basics}

The boost converter is used to "step - up" an input voltage to some higher level, required by a load. This unique capability is achieved by storing energy in an inductor and releasing it to the load at a higher voltage. These include maximum achievable output current and voltage, short circuit behavior and basic layout issues. The fundamental circuit for a boost converter consists of an inductor, diode, capacitor, switch and error amplifier with MOSFET switch control circuitry.

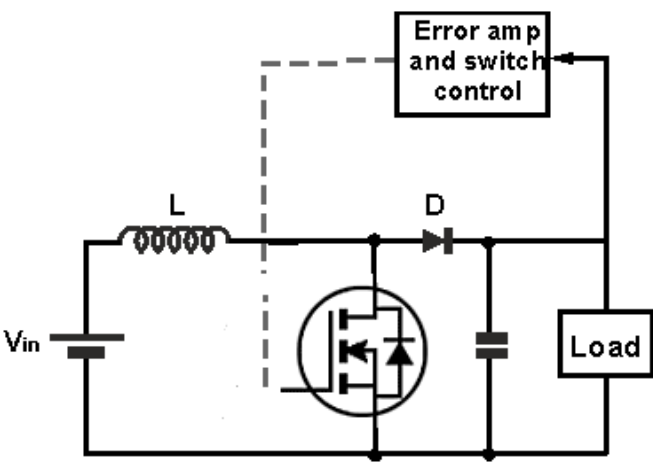

Fig:4 Boost converter block diagram

The figure 4 is shown the block diagram for the step - up boost converter operates by varying the amount of time in which inductor receives energy from the source. In the basic block diagram the operation of the boost converter can be seen that the output voltage appearing across the load is sensed by the sense / error amplifier and an error voltage is generated that controls the MOSFET switch.

\section{NOMENCLATURE:}

- $\quad$ VIN- Input voltage to regulator

- VIN- Output voltage of regulator

- IIN - Input Current to regulator

- IOUT - Output current of regulator

- R1 - Resistance of MOSFET switch

- R2 - Resistance of synchronous MOSFET ( if applicable)

- RL - Resistance of inductor

- VD - Diode voltage drop (if applicable)

- $\eta$ - Efficiency of regulator

- D - Duty cycle; ratio of MOSFET on - time to period

- DMAX - Maximum duty cycle reached by regulator

\section{B. BOOST CONVERTER OPERATION}

Figure 5 shows simplified version of the boost converter circuit. The operation of the boost converter is relatively straightforward. When the switch is in the $\mathrm{ON}$ position, the inductor output is connected to ground and the voltage Vin is placed across it. The inductor current increases at a rate equal to Vin / L. When the switch is placed in the OFF position, the voltage across the inductor changes and is equal to Vout Vin. Current that was flowing in the inductor decays at a rate equal to (Vout - Vin) $/ \mathrm{L}$

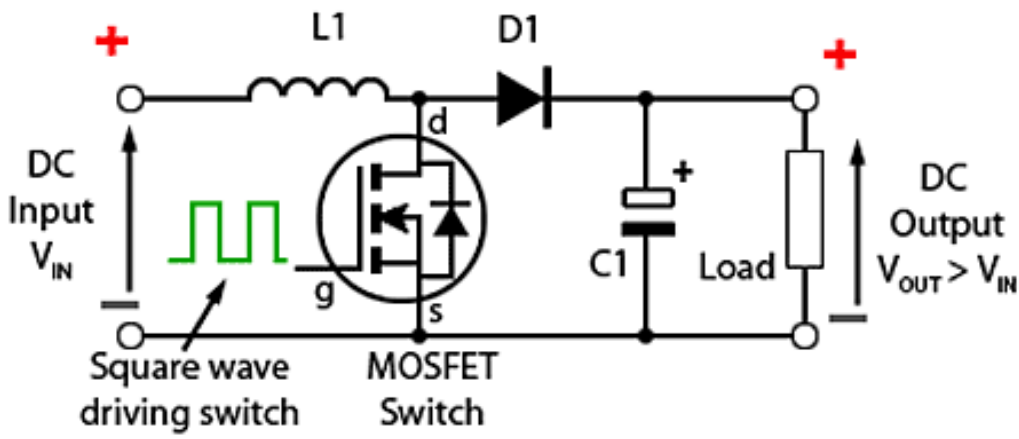

Fig:5 Boost converter circuit diagram 
The inductor is connected from the input supply to the common node between the MOSFET and diode. Therefore the peak MOSFET current is now nearly equal to the input current, not the load current. We will see shortly that the input current depends on the input and output voltages of the converter. The boost regulator is still rated based on the maximum MOSFET current.

The simplest way to calculate the input current of a boost regulator is to use the power balance equation, shown in Equation 1. for a DC/DC converter, the input and output powers are just the product of their respective currents and voltages. Adding the triangular ripple current, we arrive at Equation 2.

$$
\begin{aligned}
& \mathrm{P}_{\mathrm{N}}=\mathrm{P}_{\mathrm{our}} / \eta \\
& \mathrm{I}_{\mathrm{N}}=\mathrm{I}_{\text {OUT }} \mathrm{x}\left(\frac{\mathrm{V}_{\text {oUT }}}{\mathrm{V}_{\mathrm{NS}}}\right) \times \frac{1}{\eta}+\frac{\Delta \mathrm{I}}{2}
\end{aligned}
$$

This equation highlights the biggest stumbling block when working with boost converters: the input current will always be larger than the load current (Iout). Since the output voltage of a boost is always greater than the input voltage, the input current must be greater than the load current. This is a simple consequence of conservation of energy: the input power will be equal to the output power plus the losses. In this case the losses are taken care of by the efficiency factor, $\eta$.

If the efficiency is $90 \%$, and the peak - to - peak ripple current is $30 \%$ of the load, then Equation 2 gives:

$$
\mathrm{I}_{\mathrm{N}}=2 \mathrm{~A} \times \frac{12 \mathrm{~V}}{6 \mathrm{~V}} \times \frac{1}{0.9}+\frac{2 \mathrm{~A} \times 0.3}{2}=4.74 \mathrm{~A}
$$

\section{MAXIMUM OUTPUT VOLTAGE:}

The most fundamental limitation on the maximum output voltage for the boost is the maximum rated voltage of the MOSFET and / or diode. A more practical limitation arises from the maximum duty ratio at which the converter can operate. The duty ratio is defined as the on - time of the MOSFET divided by the total switching period. For the boost converter the approximate duty ratio (D) can be found with Equation 4. Parasitic resistance in the inductor and MOSFET, and the diode voltage drop, will set an upper limit on the duty ratio and therefore the output voltage. Equation 5 can be used to find the approximate maximum duty ratio for a given load current, input voltage, and component resistance.

$$
\begin{aligned}
& \mathrm{D}=1-\mathrm{V}_{\mathrm{N}} \times \eta / \mathrm{V}_{\text {oUT }} \\
& \mathrm{V}_{\mathrm{IN}}-\mathrm{I}_{\text {our }} \mathrm{x}\left[\mathrm{R}_{1}+\mathrm{R}_{2}+2 . \mathrm{R}_{\mathrm{I}}\right] \\
& D_{\text {max }}= \\
& \mathrm{V}_{\mathrm{IN}}+\mathrm{I}_{\text {OUT }} \mathrm{x}\left[\mathrm{R}_{1}-\mathrm{R}_{2}\right]
\end{aligned}
$$

\section{Pv Panel L Model And Characterization}

Fig 6. Shows the module cell structure of PV panel consists of a number of balanced series/parallel configurations of solar cells interconnected and abridge into a single stable unit. The balanced unit arranged in $\mathrm{X} \times \mathrm{Y}$ array, where $\mathrm{X}$ is the number of PV cells connected in series and $\mathrm{Y}$ is the number of PV cells connected in parallel. We use Ipv and Vpv to denote the current and output voltage of the PV panel, respectively. and Vpv$\mathrm{c}$ and Ipv-c to indicate the output voltage and current of a single PV cell inside the panel, correspondingly. The output voltages and currents have the following relationships: The key point of encapsulating a set of electrically connected solar cells is to protect them and their associated with wires from the typically harsh circumstances in which they are used. The metal grid on the top surface of the solar cell and the wires linked with individual solar cells may be perished by water or water vapor. Many dissimilar types of PV panel present 
and the module structure is often unlike for various types of solar cells or for different applications [6] The grid coupled single-stage converter system GCSS transfer power from photovoltaic(PV) to grid while maximum power point tracking (MPPT) continuously. The presented system has several desirable advantages such as low switching loss, high gain, and compact size that construct this GCSS appropriate for PV systems, where the PV system output voltage is low and differ with time. Design of the developed GCSS apparatus with required derivation and equations of both voltage and current control loop necessary for operation are presented [8]

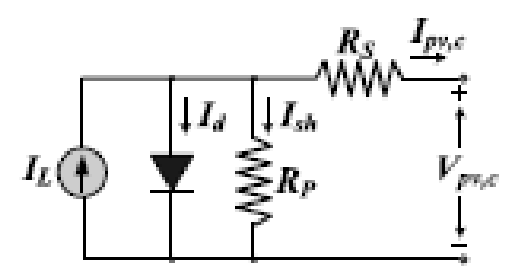

Fig 6. Equivalent PV diode module cell structure

$$
\begin{aligned}
& V_{P V}=X V_{P V-C} I_{P V} \\
& I_{P V}=Y I_{P V-C} \\
& I_{P V-C}=I_{L}-I_{D}-I_{S H} \\
& I_{L}=\frac{G}{G_{S T C}} I_{L}\left(G_{S T C}\right) \\
& I_{D}=I_{O}(T)\left[e^{L}\left[\left(V_{P V-C}+I_{P V-C}-R_{S E}\right) \frac{Q}{F K T}-1\right]\right] \\
& I_{S H}=\frac{V_{P V-C}+I_{P V-C} \times R_{S E}}{R_{S H}} \\
& I_{O}(T)=I_{O}\left(T_{S T C}\right)\left(\frac{T}{T_{S T C}}\right)^{3} \times e^{\frac{Q_{G}}{F_{G}}\left(\frac{1}{T_{S T C}}-\frac{1}{T}\right)}
\end{aligned}
$$

$\mathrm{G}=$ Solar Irradiance

$\mathrm{T}=$ Cell temperature

$\mathrm{Q}=$ Charge of electron $\left(1.602 \cdot 10^{-19}\right.$ Coulomb $)$

$\mathrm{E}_{\mathrm{G}}=$ Energy Band gab 1.1ev

$\mathrm{K}=$ Boltz man's constant $\left(1.381 \cdot 10^{-23} \mathrm{~J} / \mathrm{K}\right.$. $)$

F = Ideality factor of the diode 1.6

$\mathrm{STC}=$ Standard test condition in whitch the irradians level is $1000 \mathrm{w} / \mathrm{m}^{2}$ and cell temperature $25^{\circ}$

There are five unknown parameter which are typically not provided by PV panel manufacturer these unknown parameter are $\mathrm{I}_{\mathrm{L}}\left(\mathrm{G}_{\mathrm{STC}}\right), \mathrm{I}_{\mathrm{O}}\left(\mathrm{T}_{\mathrm{STC}}\right), \mathrm{R}_{\mathrm{SE}}, \mathrm{R}_{\mathrm{SH}}$ and $\mathrm{F}$

\section{Impact Of Pv Panel Failure/Removal}

To discuss the impact of eliminate a PV panel for the reason of maintenance or breakdown due to faults on the performance of inverter the PV RES connected to recommend 9-level H-bridge MLI for single phase module is shown in Fig. 7. In each phase of future inverter connected RES three PV panels viz., 1, 2 and 3 are employed. The sensors are provided at the boost converter end to detect the voltage and given to inverter control block. The switching logic is updated in the inverter control block to maintain the three phase balanced output voltages under faulty conditions. Three possible breakdown are considered in this section and simulation results are presented When PV panel 1 is breakdown to pump the voltage due to the fault the phase A voltage gets indistinct and level gets decrease resulting in imbalance in the three phase system. These dynamics are analyzed 
with the facilitation of simulation studies presented in the Fig 8 to 13 . To balance the system, the switching logic shown in Table I [7]

\section{Simulink Model of Photovoltaic Module with $\mathbf{H}$ bridge inverter}

PV module has been selected as a reference PV module has been simulated, in Matlab-Simulink environment The model construct based temperature and irradiation of the sunlight the diode saturation current and a series resistance which is considered depends on Shockley diode equation. By variation on irradiation of sunlight and the temperature, PV panel converts the solar energy directly into electricity which given both V-I and $\mathrm{P}-\mathrm{V}$ output characteristics. in view of the parameters, several tests have been performed at different temperature and solar irradiance values.

Fig. 7 PV panel with H-bridge inverter.

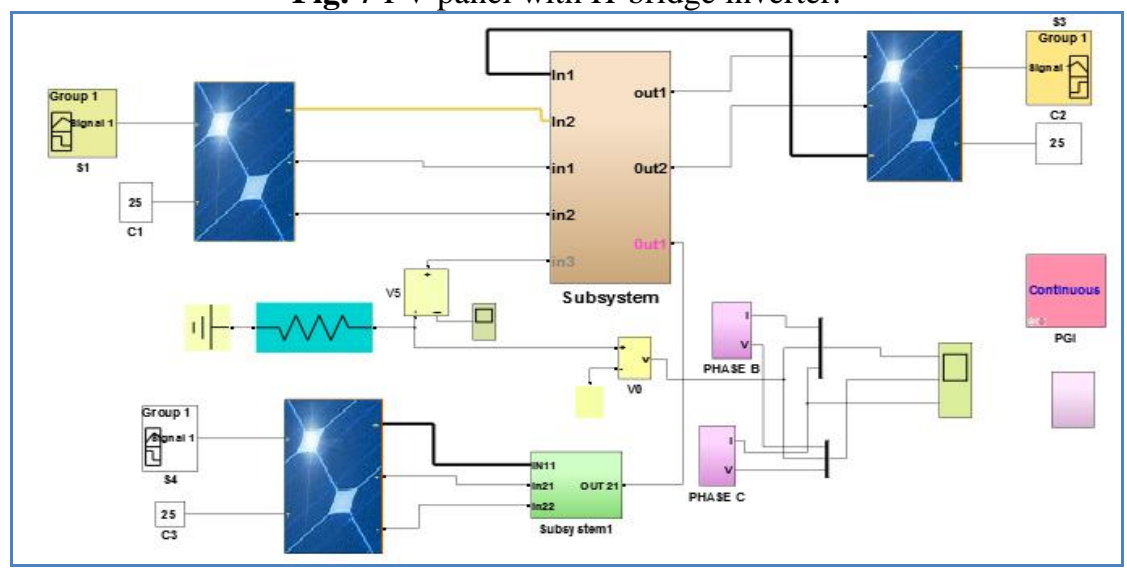

Mat lab Simulink model
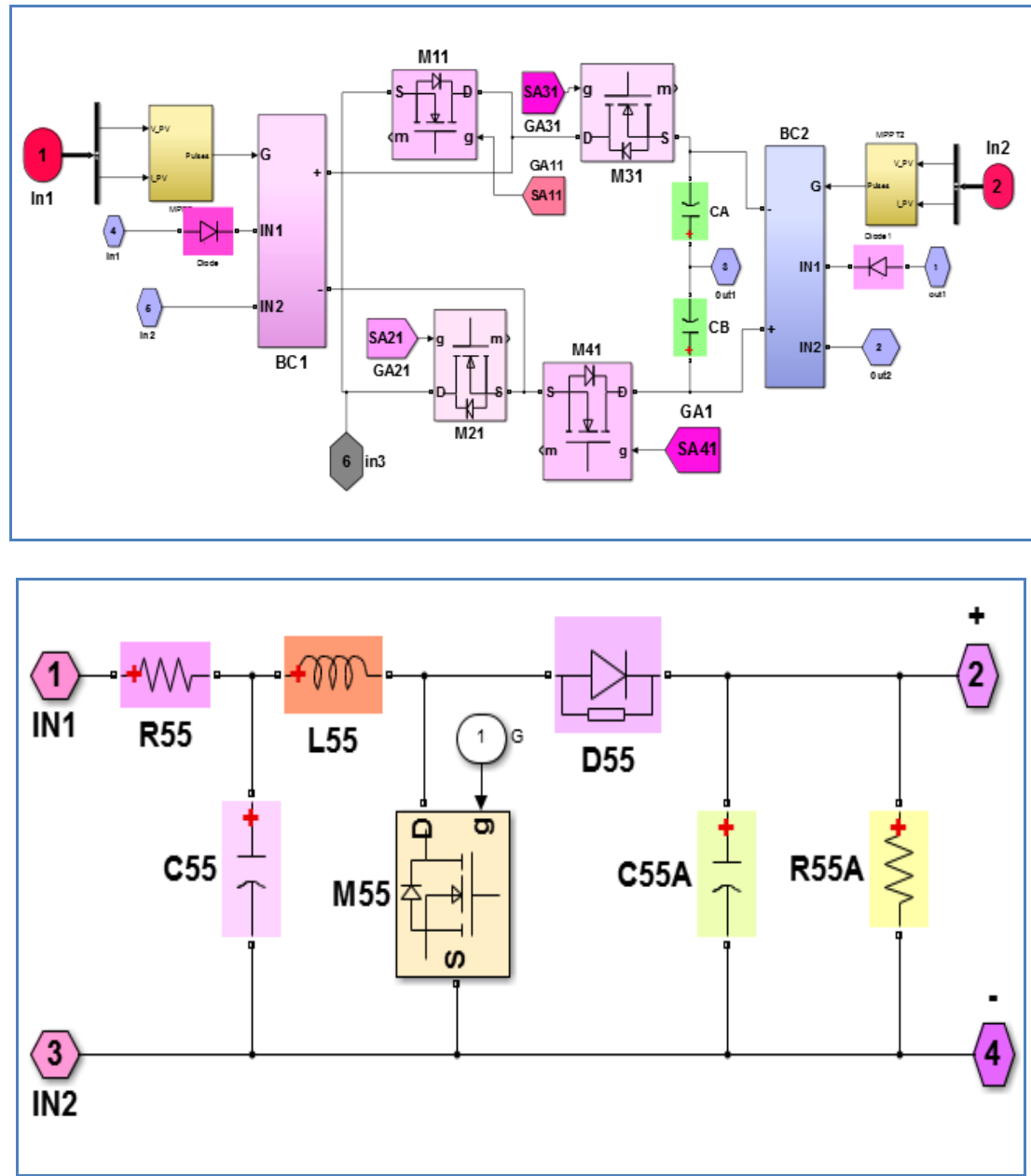


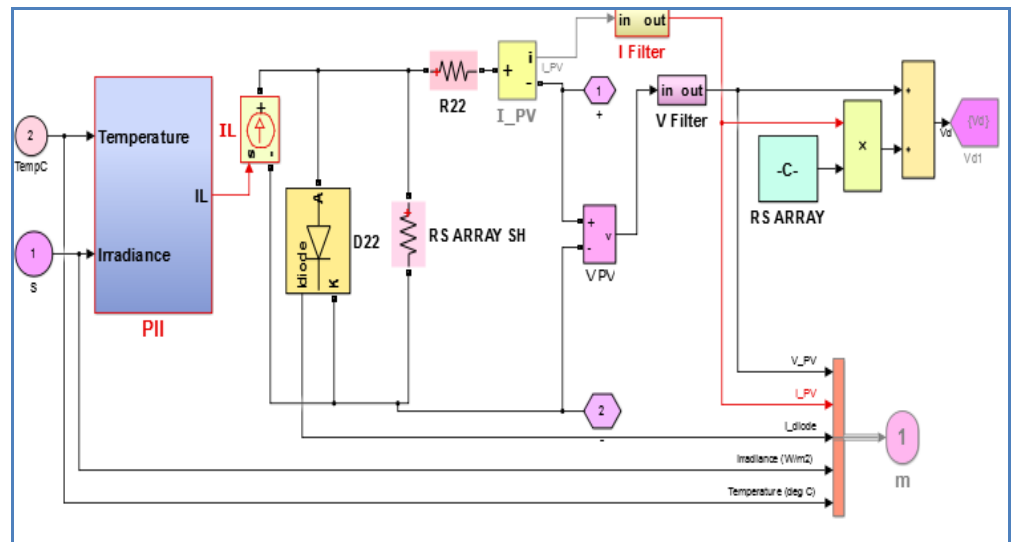

\section{Results And Discussion}

Simulated characteristics of photovoltaic array

1. P-V characteristics at various irradiance and temperature and I-V characteristics at various irradiance and temperatures
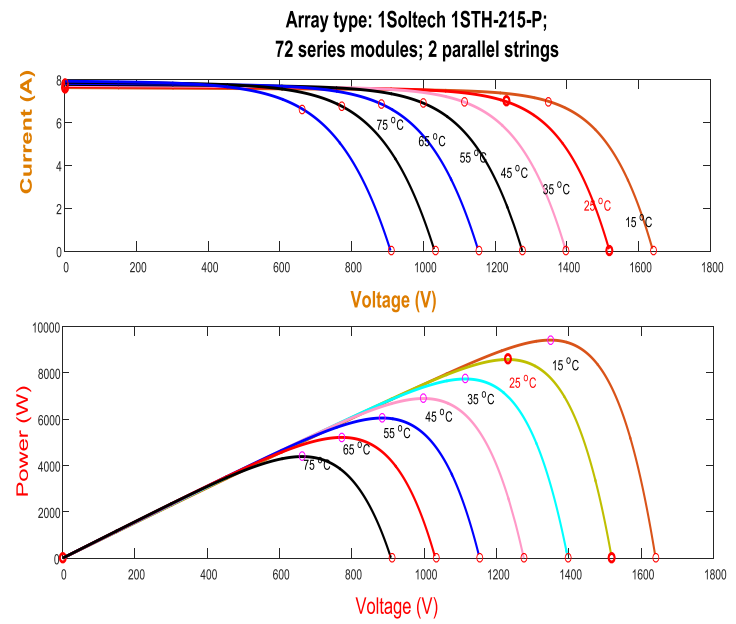

2. Curve $P-V$ at $G=1000 \mathrm{~W} / \mathrm{m} 2$ for various Temperatures Curve $I-V$ at $G=1000 \mathrm{~W} / \mathrm{m} 2$ for various Temperatures
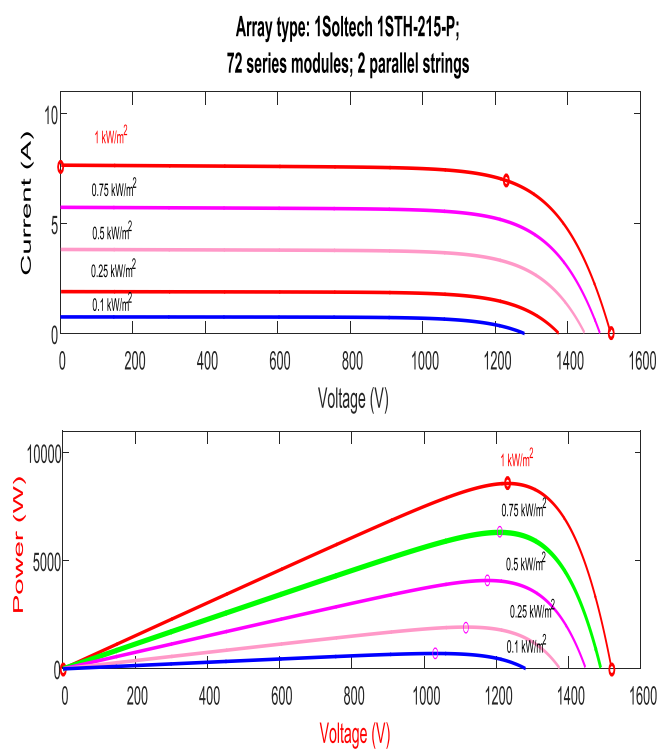

Figure 8 to 13 below shows the modeling that has been done in the Simulink with the steps that involved. 
Simulated output 9-level operation: voltage waveform

(1) Boosted PV output to TTL

(2) inverter $V T$ and to MHB modules in all phases

\section{Simulated output filter}

Simulated output 9-level operation:

(1) Load currents $I A, I B$ and $I C$,

(2) Line voltages $V A B, V B C$ and $V C A$

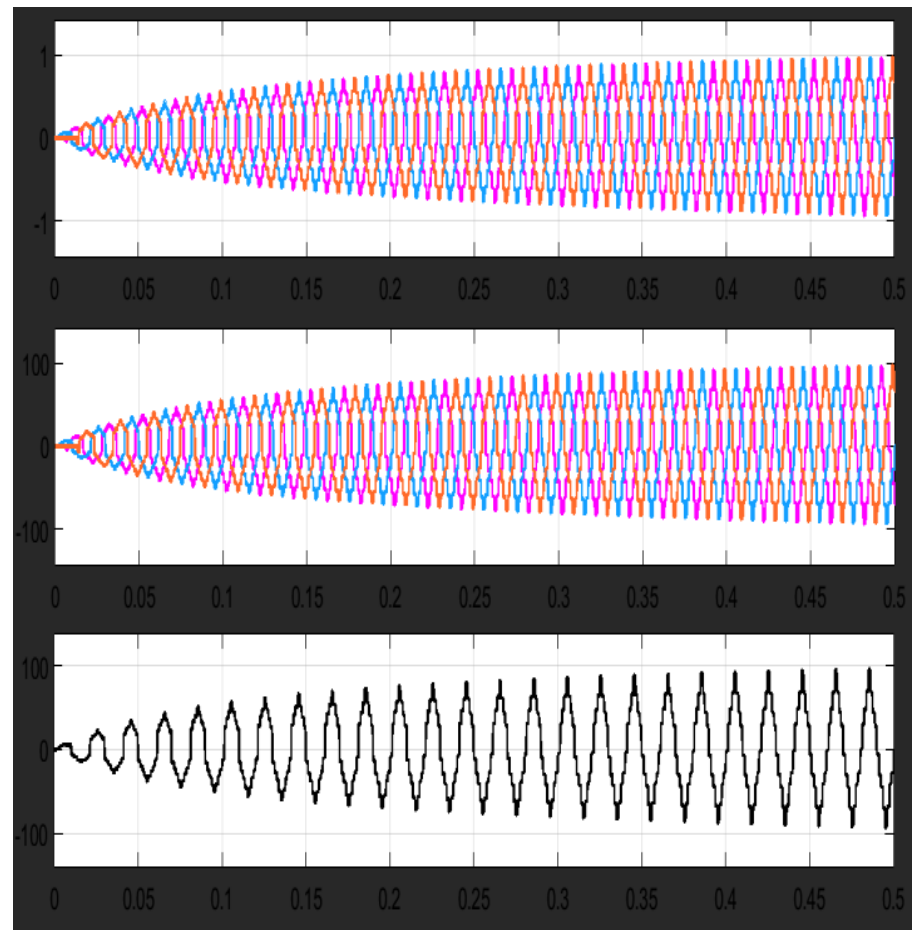

(1) Boosted PV output to TTL

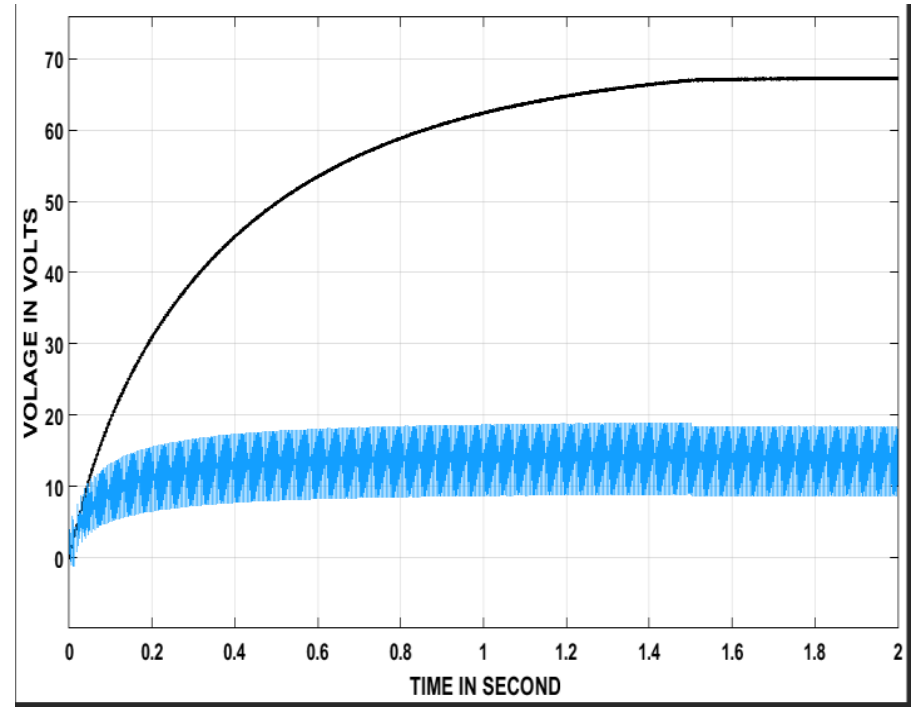

\section{Conclusion}

In this paper, the proposed nine level $\mathrm{H}$ - bridge modular MLI is interconnected with PV storage system for the prediction of output power. The MOSFET switches in the $\mathrm{H}$ - bridge cells are significant in reducing current ripples for the motor drives and improve the efficiency. The boost converter has been interfaced to boost PV power capacity. Finally the simulation result shows the boosted PV output power, load currents and line voltage for different temperatures of photovoltaic array and validated for the proposed topology. 


\section{References}

[1]. D. T. Ton, C. J. Hanley, G. H. Peek, and J. D. Boyes, "Solar energy grid integration systems-Energy storage (SEGIS-ES)," Sandia National Laboratories, Jul. 2008.

[2]. P. Denholm, E. Ela, B. Kirby, and M. Milligan, "The role of energy storage with renewable electricity generation," National Renewable Energy Laboratory, Rep. TP-6A2-47187, 2010.

[3]. C.Whitaker, J.Newmiller,M. Ropp, and B.Norris, "Distributed photovoltaic systems design and technology requirements," Sandia NationalLaboratories, 2008.

[4]. Trudie Wang, Haresh Kamath, and Steve Willard "Control and Optimization of Grid-Tied Photovoltaic Storage Systems Using Model Predictive Control” IEEE Transactions On Smart Grid, Vol. 5, NO. 2, March 2014

[5]. V. Raghunathan, A. Kansal, J. Hsu, J. Friedman, and M. B. Srivastava, "Design considerations for solar energy harvesting wireless embedded systems," in Proc. IPSN, Boise, ID, USA, 2005,pp. 457-462.

[6]. Xue Lin, Yanzhi Wang, Naehyuck Chang, and Massoud Pedram, "Concurrent Task Scheduling and Dynamic Voltage and Frequency Scaling in a Real-Time Embedded System With Energy Harvesting” IEEE Transactions on Computer-Aided Design of Integrated Circuits and Systems, Vol. 35, No. 11, November 2016

[7]. Ye Zhao; J. de Palma, J. Mosesian, R. Lyons, and B. Lehman, "Line-Line Fault Analysis and Protection Challenges in Solar Photovoltaic Arrays," IEEE Trans. Ind. Electron., vol.60, no.9, pp.3784-3795, Sept. 2013.

[8]. T. Sreekanth,N. Lakshminarasamma andMahesh K. Mishra "A Single-Stage Grid-Connected High Gain Buck-Boost Inverter With Maximum Power Point Tracking" IEEE Transactions on Energy Conversion vol. 32, Issue: 1, March 2017

[9]. K. K. Gupta, and S. Jain, - Theoretical analysis and experimental validation of a novel multilevel inverter topology for renewable energy interfacing applications, ॥ J. Renewable Sustainable Energy, 4, 013113, 2012.

[10]. G. Buticchi, D. Barater, E. Lorenzani, C. Concari, and G. Franceschini, -A Nine-Level Grid-Connected Converter Topology for Single-Phase Transformerless PV Systems, ॥IEEE Trans. Ind. Electron., vol. 61, no. 8, pp. 3951-3960, August 2014.

[11]. N. A. Rahim, K. Chaniago, and J. Selvaraj, —-SinglePhase Seven-Level Grid-Connected Inverter for Photovoltaic System,\| IEEE Trans. Ind. Electron., vol. 58, no. 6, pp. 2435-2443, June 2011.

[12]. J. Selvaraj, and N. A. Rahim, - A novel pulse width modulation for grid-connected multilevel inverter,\| J. Renewable Sustainable Energy, 1, 053102, 2009.

[13]. Jinn-Chang Wu, and Chia-Wei Chou, —A Solar Power Generation System With a Seven-Level Inverter,\| IEEE Trans. Power Electron., vol. 29, no. 7, pp. 3454-3462, July 2014.

[14]. E. Babaei, M. F. Kangarlu, and M. Sabahi, - Extended multilevel converters: an attempt to reduce the number of independent DC voltage sources in cascaded multilevel converters, $\|$ in Power Electronics, IET, vol. 7, no. 1, pp. 157-166, Jan. 2014.

[15]. E. Babaei, and S. H. Hosseini, - Charge balance control methods for asymmetrical cascade multilevel converters, in Proc. ICEMS, Seoul, Korea, 2007, pp. 74-79. 